\title{
Terra firma-form dermatozu
}

\author{
Terra firma-forme dermatosis
}

\section{Aycan Özden Sezgin, Bengü Gerçeker Türk*, Banu Yaman**, Tuğrul Dereli*}

Orhangazi Devlet Hastanesi, Deri ve Zührevi Hastalıklar Kliniği, Bursa, Türkiye

\author{
*Ege Üniversitesi Tıp Fakültesi, Deri ve Zührevi Hastalıklar Anabilim Dalı, **Patoloji Anabilim Dalı, İzmir, Türkiye
}

\section{Özet}

Terra firma-form dermatozu (TFFD) kir benzeri kahverengi hiperpigmente papillamatöz plaklarla karakterize etyolojisi tam olarak bilinmeyen, asemptomatik bir keratinizasyon bozukluğudur. Lezyonların gelişimi hijyen bozukluğu ile ilişkisizdir. Hastalığın en önemli özelliği lezyonların susabunla giderilemezken sadece \%70 izopropil veya etil alkolle silinebilmesidir. Burada daha önce epidermal nevüs tanısı alan terra firma-form dermatozlu bir çocuk olgu sunulmaktadır. (Türkderm 2013; 47: 187-9)

Anahtar Kelimeler: Terra firma-form dermatozu, Duncan'ın kirli dermatozu, çocukluk çağı

\section{Summary}

Terra firma-forme dermatosis (TFFD), which is characterized by dirt like brown hyperpigmented papillomatous plaques, is an asymptomatic keratinization disorder of an unknown etiology. Development of lesions is not associated with inadequate hygiene. The most important feature of the disease is that the lesions cannot be removed by washing with soap and water, while they can only be removed by rubbing with $70 \%$ isopropyl alcohol or ethyl alcohol. Here, we present a child with terra firma-forme dermatosis who has been previously diagnosed with epidermal nevus. (Turkderm 2013; 47: 187-9)

Key Words: Terra firma-forme dermatosis, Duncan's dirty dermatosis, pediatric

\section{Giriş}

Terra firma-form dermatozu (TFFD) daha çok çocuklarda rastlanan etyolojisi tam olarak bilinmeyen bir keratinizasyon bozukluğudur. Latince olan "terra firma" kuru toprak, kuru yüzey anlamına gelmektedir1-3. "Duncan'ın kirli dermatozu" olarak da isimlendirilen bu hastalıkta lezyonlar genellikle boyun ve gövdede yerleşim göstermekte olup saçlı deri ve ekstremite alanlarında da gözlenebilmektedir ${ }^{4}$. Kir benzeri hiperpigmente verrüköz, papillomatöz veya retiküle plaklarla karakterize lezyonlar su-sabunla giderilemezken, izopropil veya etil alkolle basınç uygulayarak silindiğinde gerilemekte- dir ${ }^{4}$. TFFD tanısı alan hastalarda herhangi bir hijyen bozukluğu bulunmamaktadır. Burada terra firma-form tanısı alan yedi yaşında bir kız olgu sunulmaktadır.

\section{Olgu}

Yedi yaşında kız hasta, her iki uyluk ön yüzünde üç yıl önce başlayıp her iki dize doğru uzanan kahverengi lekeler nedeniyle başvurdu. Haftada 2-3 defa banyo yapan, hijyen bozukluğu olmayan hastanın lezyonlarının kir olduğu düşünülerek bunları gidermek için çeşitli sabunların yanı sıra

Yazışma Adresi/Address for Correspondence: Dr. Aycan Özden Sezgin, Orhangazi Devlet Hastanesi, Deri ve Zührevi Hastaliklar Kliniği, Bursa, Türkiye

Tel.: +90 2245731270 E-posta: aycanozdemir@yahoo.com Geliş Tarihi/Received: 23.05.2011 Kabul Tarihi/Accepted: 04.08.2011 
annesi tarafından keseleme işlemi de denenmişti. Özgeçmişinde ve soygeçmişinde özellik bulunmamaktaydı. Birkaç ay önce başvurduğu bir başka dermatoloji kliniğinde lezyonların epidermal nevus olabileceği belirtilmişti. Dermatolojik muayenede bilateral femoral alanlarda foliküllerin korunduğu, retiküler pigmente maküler lezyonlar görüldü (Resim 1). Histopatolojik incelemede epidermiste hafif papillomatoza eşlik eden belirgin lamellar hiperkeratoz ve fokal alanlarda girdap yapıları oluşturan kompakt ortokeratoz alanları izlendi. Parakeratoz alanı veya inflamasyon görülmedi (Resim 2A-B). Uygulanan periodik asid-Schiff (PAS) boyaması ile biyopsi örneğinde mantar spor veya hifleri tespit edilmedi. Histopatolojide saptanan belirgin hiperkeratoz nedeniyle hastada terra-firma form dermatozu düşünülerek lezyonlara tanısal amaçı alkollü pamukla silme uygulandı. Tüm lezyonların hafif basınçla alkol uygulaması sonrasında gerilediği görüldü (Resim 3A-B).

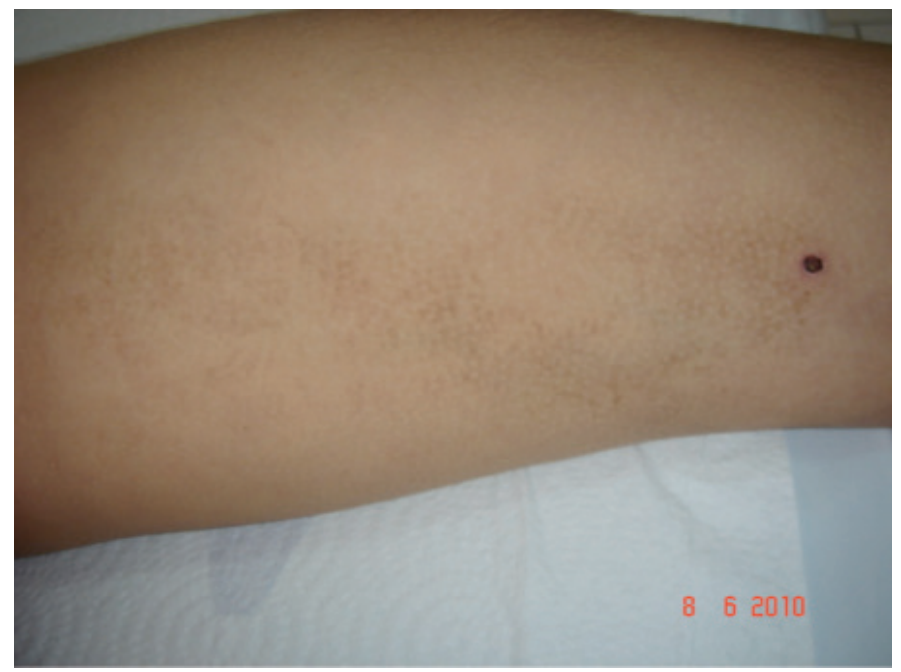

Resim 1. Sol femoral bölge anteriorunda dağınık bir şekilde yerleşim gösteren foliküllerin korunduğu, retiküler pigmente maküler lezyonlar

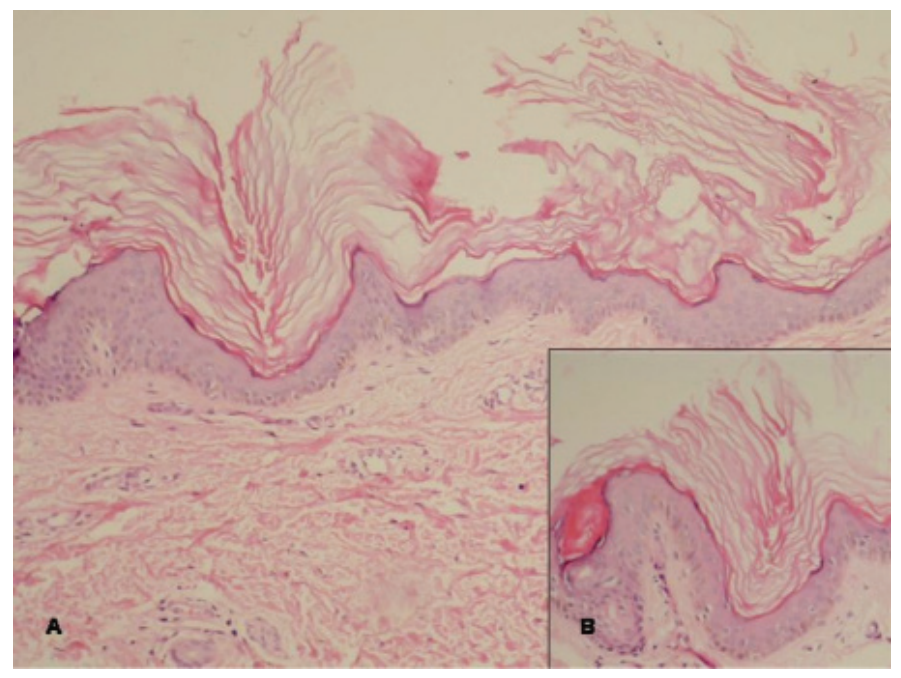

Resim 2. A: Epidermiste papillamatoz ile birlikte lamellar hiperkeratoz (H\&E x100), B: Lamellar hiperkeratoz ve bir alanda kompakt ortokeratoz $(H \& E \times 200)$

\section{Tartışma}

TFFD etyolojisi tam olarak bilinmeyen bir keratinizasyon bozukluğudur. Kozmetik problem oluşturan bu hastalığa, biyopsi alımı sırasında alkol kullanııırsa tesadüfen tanı konulabilmektedir4. Bunun dışında TFFD ön tanılarda akla gelmedikçe kolaylıkla atlanabilmektedir. Bazı olgularda alkolle hafifçe silmek yeterliyken bazı olgularda da lezyonları gidermek için basınçla silmek gerekebilmektedir 5 .

Konuyla ilgili çok fazla yayın olmamasına rağmen bildirilenden daha fazla sayıda hasta olduğu tahmin edilmektedir. Yabancı literatürde TFFD tanısıyla bildirilen biri Türkiye'den (2) olmak üzere toplam 17 olgu bulunmaktadır. Bunlardan 12'si yirmi yaşından küçük (1-9) olup tüm hastaların yaşları dört ay ile 72 yaş arasında değişmektedir. Hastalık süresi altı hafta ile birkaç yıl arasında değişiklik göstermektedir. Lezyonlar boyunda3-6, ekstremitelerde1,5-8, gövdede2,5,6,8, umblikusta1,6, saçlı deride5, aksillada6, mons pubiste ${ }^{9}$ yerleşim gösterebilmektedir. Literatürdeki iki olguda yaz aylarında yoğun güneş maruziyeti sonrasında lezyonların başladığı belirtilmiştir7,8. Olgumuzda ise lezyonların gelişiminden önce güneşe maruziyet öyküsü bulunmamakta idi.

Hastalığın tipik patolojik bulguları fokal, girdap yapıları oluşturan kompakt ortokeratoz ve stratum korneumda keratin globülleri olarak tanımlanmıştır. Özellikle girdap yapıları oluşturan ortokeratozun tanı

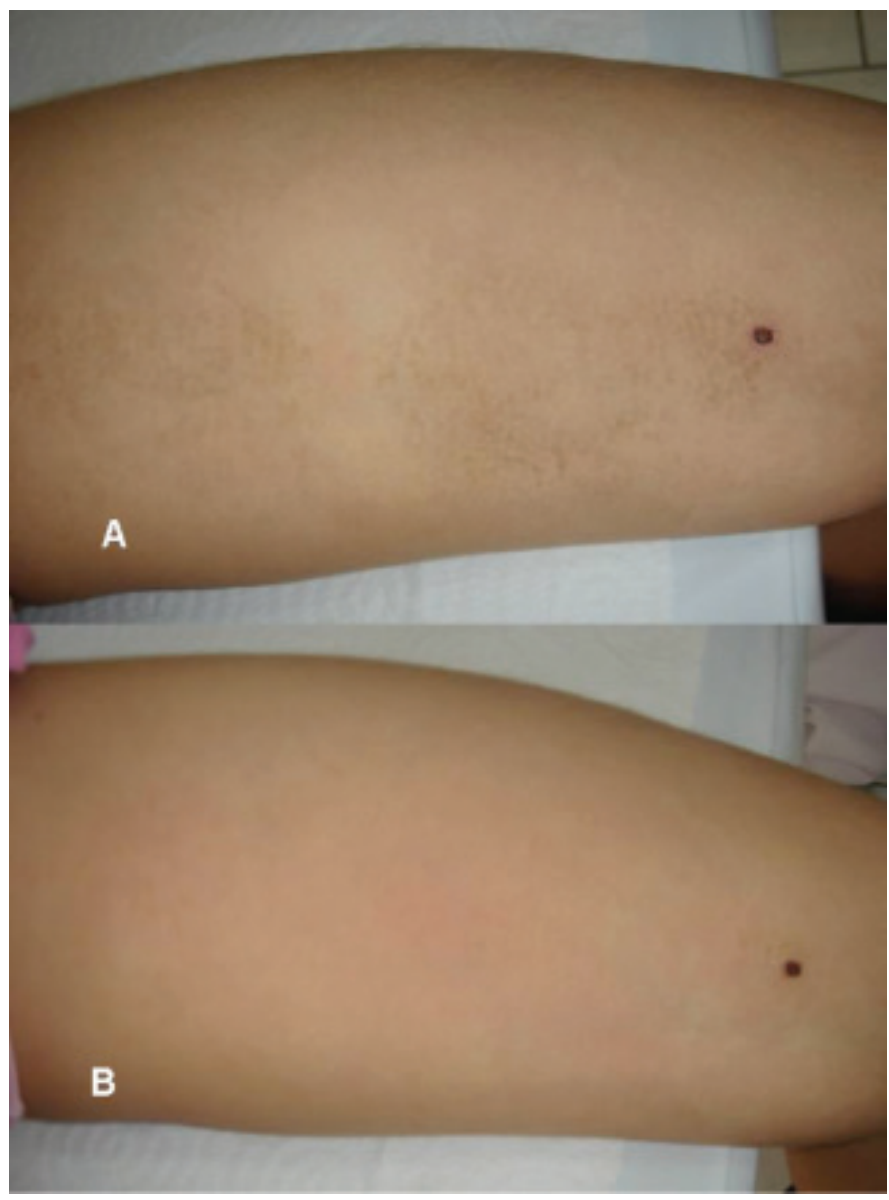

Resim 3. A: Lezyonun ortasını horizontal şekilde alkollü pamukla sildikten sonraki görünüm, B: Sol uyluktaki lezyonun tamamının alkollü pamukla silindikten sonraki görünümü 
koydurucu olduğu belirtilse de Akkash ve ark. izlenen ortokeratozun hastalığa özgü olmadığını belirtmişlerdir6. Girdap yapıları oluşturan ortokeratozun dermatozis neglektada görülmemesi iki hastalığın ayrımasını sağlamaktadır. Lamellar hiperkeratoz, hafif akantoz, bazal tabaka ve hiperkeratotik alanların hipermelanozisi histopatolojik olarak görülebilen diğer bulgulardır. PAS boyama ile stratum korneumda maya sporları görülebilmektedir. En sık saptanan maya malassezia furfur olarak belirtilmiştir. Parakeratoz ve inflamatuar infiltrasyon bulunmamaktadır $4-6,8$.

Sunulan olgu literatürdeki yaş dağılımıyla uyumlu olarak yirmi yaşından küçüktür. Hastalık süresi üç yıl olup lezyonlar alt ekstremitede lokalizedir. Hastada tetikleyici bir sebep saptanmamış ve sekiz aylık takibinde nüks görülmemiştir. TFFD için karakteristik olan fokal alanlarda girdap yapıları oluşturan kompakt ortokeratoz alanları izlenmiş olup PAS boyama ile spor veya hif tespit edilmemiştir.

Ayırıc tanıda başlıca dermatozis neglekta, akantozis nigrikans, nörodermatit, iktiyoz, tinea versikolor, Gougerot-Carteaud sendromu, epidermal nevus yer almaktadır. Dermatozis neglektalı olgularda TFFD'den farklı olarak hijyen bozukluğu mevcuttur. Lezyonlar hem su-sabun hem de alkolle silinebilmektedir.

TFFD tedavisiz bırakıldığında daha da belirginleşerek devam etmektedir. Lezyonlar özellikle boyun yerleşimi gösterdiğinde olgularda akantozis nigrikans düşünülerek gereksiz endokrinolojik tetkikler yapılabilmektedir5. Tanının ve tedavinin aynı anda yapılabildiği bu hastalığın pigmentasyon bozukluklarının ayırıcı tanısında akılda bulundurulması gereksiz tetkiklerin yapılmasını önlemekte, ardından lezyonların alkolle silinmesi ile tanı biyopsiye bile gerek kalmaksızın kolaylıkla konulabilmektedir.

\section{Kaynaklar}

1. Berk DR, Bruckner AL: Terra firma-forme dermatosis in a 4-month-old girl. Pediatr Dermatol. 2011;28:79-81

2. Oztürk F, Kocabaş E, Ertan P, Ermertcan AT: Terra firma-forme dermatosis. Cutan Ocul. Toxicol 2010;29:303-5.

3. O'Brien TJ, Hall AP: Terra firma-forme dermatosis. Australas J Dermatol 1997;38:163-4.

4. Duncan WC, Tschen JA, Knox JM: Terra firma-forme dermatosis. Arch Dermatol. 1987;123:567-9.

5. Browning J, Rosen T: Terra firma-forme dermatosis revisited. Dermatol Online J. 2005;11:15.

6. Akkash L, Badran D, Al-Omari AQ: Terra firma forme dermatosis. case series and review of the literature. J Dtsch Dermatol Ges 2009;7:102-7.

7. Pavlovic MD, Dragos V Potocnik M, Adamic M: Terra firma-forme dermatosis in a child. Acta Dermatovenerol Alp Panonica Adriat 2008;17:41-2.

8. Guarneri C, Guarneri F, Cannavò SP: Terra firma-forme dermatosis. Int J Dermatol 2008;47:482-4

9. Raveh T, Gilead LT, Wexler MR: Terra firma forme dermatosis. Ann Plast Surg. 1997;39:542-5 